\title{
Hacia una conceptualización de los videojuegos como discursos multimodales electrónicos ${ }^{*}$
}

\author{
Felipe Pereira Henríquez ${ }^{\star \star}$ \\ Teresa Alonzo Zúñiga*** \\ Recibido: 2016-07-21 Enviado a pares: 2016-08-23 \\ Aprobado por pares: 2016-09-06 Aceptado: 2016-11-07 \\ DOI: 10.22395/angr.v15n30a2
}

\begin{abstract}
Resumen
Los videojuegos son prácticas culturales instaladas en nuestras sociedades que requieren de una mirada crítica y especializada; las líneas de investigación que han abordado este fenómeno transitan entre los estudios culturales, la ludología, los estudios narratológicos, la teoría de diseño de juegos y la semiótica del videojuego. Todas estas perspectivas han entregado conceptualizaciones diferentes respecto de este objeto de estudio, yendo desde visiones que van desde considerarlos como medios de expresión contemporáneos hasta promotores de la violencia, el aislamiento y el fracaso escolar

El presente trabajo considera que los videojuegos implican nuevas formas de discursos que no solo se restringen al canal verbal, sino que también contemplan otros recursos semióticos. En concordancia con lo anteriormente expuesto, el objetivo de este escrito es exponer una conceptualización teórica del videojuego desde una perspectiva multimodal y lingüística. Para esto se revisan distintas definiciones sobre videojuego, el concepto de discurso y discurso electrónico-digital y, finalmente, se abordan los recursos semióticos presentes en estos. Esta revisión permite configurar una definición de videojuego como un discurso multimodal electrónico.
\end{abstract}

Palabras clave: videojuego, multimodalidad, discurso, recursos semióticos, discurso

Este artículo es uno de los productos del proyecto de investigación "Educación y videojuegos: ¿Qué se puede aprender desde estos discursos multimodales electrónicos?" patrocinado por la Universidad Viña del Mar, entre los años 2015 y 2016. El objetivo principal de esta investigación se centra en determinar cuáles son las características de los videojuegos que los hacen llamativos para niños y adolescentes y la forma en que los estudiantes de Pedagogía incluyen en sus discursos pedagógicos los principios innovadores de estos. CHILE

. Profesor de Castellano, licenciado en Lengua y Literatura Hispánica y doctor en Lingüística, ambos grados otorgados por la Pontificia Universidad Católica de Valparaíso (Chile). Se ha desempeñado como docente en carreras de Castellano y Educación Básica en la PUCV y ha trabajado en el área de perfeccionamiento docente. Actualmente, trabaja como jefe de Carrera de Lenguaje y Literatura en la Universidad Viña del Mar. Sus intereses científicos se han centrado en el ámbito de la comprensión y producción de discursos multimodales, específicamente se ha dedicado a estudiar el videojuego como discurso multimodal electrónico. Universidad Viña del Mar fpereira@uvm.cl

... Teresa Alonzo Zúñiga es profesora de Castellano y Comunicación y obtuvo los grados de licenciada en Educación y magíster en Lingüística Aplicada por la Pontificia Universidad Católica de Valparaíso, Chile. Ha trabajado en formación inicial y perfeccionamiento docente en el área de la comprensión y producción de textos en distintas universidades. Su línea de estudio se ha enfocado en la comprensión y producción de textos. Actualmente se encuentra cursando el Doctorado en Lingüística en la PUCV. Pontificia Universidad Católica de Valparaíso teresa.alonzo@gmail.com 


\title{
Towards a conceptualization of videogames as electronic multimodal discourses
}

\begin{abstract}
Videogames are cultural practices installed in our societies that require a specialized and critical view. Lines of research which aboard this phenomenon range from cultural studies, ludology, narratological studies, game design theory and videogame semiotics. All these perspectives have provided different conceptualisations in relation to this object of study, ranging from views that consider it as contemporary ways of expression to promoters of violence, isolation and school failure.

The present study considers that videogames imply new forms of discourse which are not only restricted to the verbal channel, but also take into account other semiotic resources. According to what was previously exposed, the objective of this paper is to present theoretical conceptualisation about the videogame from a multimodal and linguistic perspective. For this reason, different definitions of videogame are revised as well as the concept of discourse and digital-electronic discourse, and finally, semiotic resources present on these aspects are aboarded. This review allows to set up a definition of videogame as a multimodal electronic discourse.
\end{abstract}

Key words: videogame, multimodality, discourse, semiotic resources, multimodal electronic discourse. 


\section{Introducción}

La tecnologización de la sociedad actual hace pensar que resulta casi imposible vislumbrar la vida moderna sin la utilización de productos o artefactos tecnológicos. La creciente propagación de consolas de mesa, PC, celulares y consolas de mano, ha puesto en evidencia que los videojuegos han cobrado relevancia tanto por los recursos semióticos que utilizan como por las tramas que los constituyen. Asimismo, desde su invención en la década del 60 y su consolidación en las décadas posteriores, los videojuegos generaron una adhesión en niños, jóvenes y adultos, transformándose en la actualidad, en objetos relevantes para la cultura, el entretenimiento y el ocio.

Plantear una única definición respecto a qué son los videojuegos resulta tan complejo como señalar que este fenómeno puede estudiarse desde una disciplina particular. Kirriemur y Mcfarlane (2005) señalan que en el estudio de estos nuevos medios confluyen la informática, la psicología, la educación, la sociología y los estudios culturales. Estos investigadores precisan que los videojuegos son sistemas complejos en términos de gráficas, interacción y narrativa, que pueden ser categorizados en diferentes géneros de acuerdo con su tipo.

De acuerdo con la idea planteada en el párrafo anterior, el objetivo de este artículo es exponer una conceptualización teórica y discursiva del videojuego desde la lingüística y la multimodalidad. Se revisan diferentes posiciones teóricas para alcanzar el objetivo, las que se plasman en los apartados de este escrito. El primero se focaliza en una revisión de las perspectivas de estudio sobre el videojuego. El segundo da cuenta de la noción de discurso desde el foco textual, comparándolo con los nuevos discursos electrónicos. El tercero desarrolla los conceptos de recurso y orquestación semiótica, desde la semiótica social. El cuarto, por su parte, se enfoca en los aspectos metodológicos que permiten plantear a los autores de este texto una definición del videojuego como discurso multimodal electrónico. Posterior a estos acápites de corte teórico, se señalan las conclusiones más relevantes de este escrito.

\section{Videojuegos: breve panorama de las conceptualizaciones y los enfoques sobre este objeto de estudio}

El estudio de los videojuegos ha transitado por diferentes visiones que van desde considerarlos como medios de expresión contemporáneos hasta promotores de la violencia, el aislamiento y el fracaso escolar (López, 2013). De acuerdo con Kirriemur y Mcfarlane (2005) los videojuegos son sistemas complejos en términos de gráficas, interacción y narrativa que pueden ser categorizados en diferentes géneros de acuerdo con su tipo. Desde otra mirada, Mitchell y Savill-Smith (2005); Nussbaum, Rosas, Cumsille, Marianov, Correa, Flores y Salinas (2003), señalan que para definir los videojuegos deben ser acotados dos términos. Primero, el jugar (Play) y luego, el juego (Game). Jugar es una acción que proporciona placer, incrementa la participación y permite aprender. En términos piagetianos, jugar es fundamental para estabilizar los procesos que son esenciales para el desarrollo de estructuras cognitivas. En términos de Vigotsky, jugar es una experiencia 
privilegiada de aprendizaje debido a que la relación con otros permite crear y mejorar la zona de desarrollo próximo. El juego, en cambio, es entendido como un sistema que aporta reglas, condiciones y algunos aspectos de la competición.

Una tercera conceptualización de este objeto de estudio plantea que un videojuego se compone de la interacción entre recursos visuales y sonoros y, además, requiere de sistemas de respuesta háptica tales como mouse, joystick, guantes, teclados, trajes u otros dispositivos. Estos facilitan y permiten la interacción hombre-máquina (De Aguilera E Mañas, 2001 y Sánchez, Sáenz \& Garrido, 2010).

Así como se sugieren diferentes definiciones de videojuego, la literatura especializada en esta área plantea que las líneas de investigación sobre este han deambulado entre dos polos (De Aguilera \& Mendiz, 2003; Pérez, Postigo \& Sedeño, 2003 y Mendiz, Pindado, Ruiz \& Pulido 2003). Por una parte, están los investigadores que analizan los efectos nocivos de los videojuegos, mientras que por otra, quienes defienden los efectos positivos. De Aguilera y Mendiz (2003), señalan que durante gran parte de la década del 80, las investigaciones sobre videojuegos centraron su atención en los efectos adictivos de estos. De este modo, durante muchos años se señaló que los videojuegos generan adicción, son promotores del sedentarismo, inhiben las actividades al aire libre, impiden hacer deportes, recortan las horas de estudio e, incluso, desarrollan actitudes violentas en niños y jóvenes (Pérez et al., 2003; Mendiz et al.,2003).

A partir de la década del noventa, el panorama respecto a los videojuegos comienza a dar un giro y se centra en los efectos positivos que estos promueven. Para Gómez, Esther y Turci (2003) surge una serie de estudios relacionados con la potenciación de las capacidades cognoscitivas, la adquisición de destrezas y habilidades, la difusión de ideas y valores y, por último, la modelización de conductas. En esta misma línea, Mendiz, et al., (2003) plantea que el uso de videojuegos supone una ayuda para el desarrollo intelectual y favorece habilidades cognitivas tales como la atención, la percepción espacial y la memoria, mientras que en el plano de las destrezas y habilidades, se ha reconocido que estos desarrollan el discernimiento visual, mejoran el desarrollo lógico inductivo y potencian las competencias para la gestión de recursos y manejo de la información (Bernat, 2008). Bajo esta misma perspectiva, el Grupo F9 (2000) plantea una serie de habilidades que se potencian con el uso de los videojuegos. Entre las más relevantes figuran las habilidades para la resolución de problemas, habilidades metacognitivas, habilidades creativas y habilidades para la toma de decisiones.

Desde el plano de la educación, Pérez et al., (2003) señalan que los videojuegos educativos son programas que combinan actividades lúdicas con contenidos de la educación. Para estos investigadores, existen tres criterios para su clasificación, a saber: los diferentes tipos de contenidos que pueden trabajarse en el aula, las actividades cognitivas que desarrollan y su función en la estrategia didáctica. De esta forma, bajo el primer criterio se consideran los contenidos conceptuales, actitudinales o procedimentales que es posible desarrollar con la utilización de videojuegos en el aula. En el segundo criterio, se concentran los videojuegos que desarrollan el control psicomotriz, la observación, 
la memorización, el cálculo, el análisis, la comprensión, la resolución de problemas, la creación, la exploración y la experimentación. Por último, en el tercer criterio, están los videojuegos que permiten entrenar, motivar, evaluar, proveer recursos, entretener, experimentar, instruir, explorar e informar.

Como se desprende de lo planteado en los párrafos que preceden, el estudio de los videojuegos ha deambulado entre diferentes visiones. De acuerdo con López (2013), esta área se consolida con la disciplina denominada Game Studies, inaugurada con los planteamientos de Aarseth (1997), quien propone el concepto de cibertexto y texto ergódico como sinónimos de videojuego. Desde otra perspectiva, Pérez Latorre (2010) propone diferentes líneas teóricas que han estudiado el fenómeno de los videojuegos. De acuerdo con este autor, los estudios más promisorios son la ludología, los estudios narratológicos, la teoría de diseño de juegos y la semiótica del videojuego. En la figura 1, se presenta un esquema que da cuenta de estas diferentes líneas de estudio.

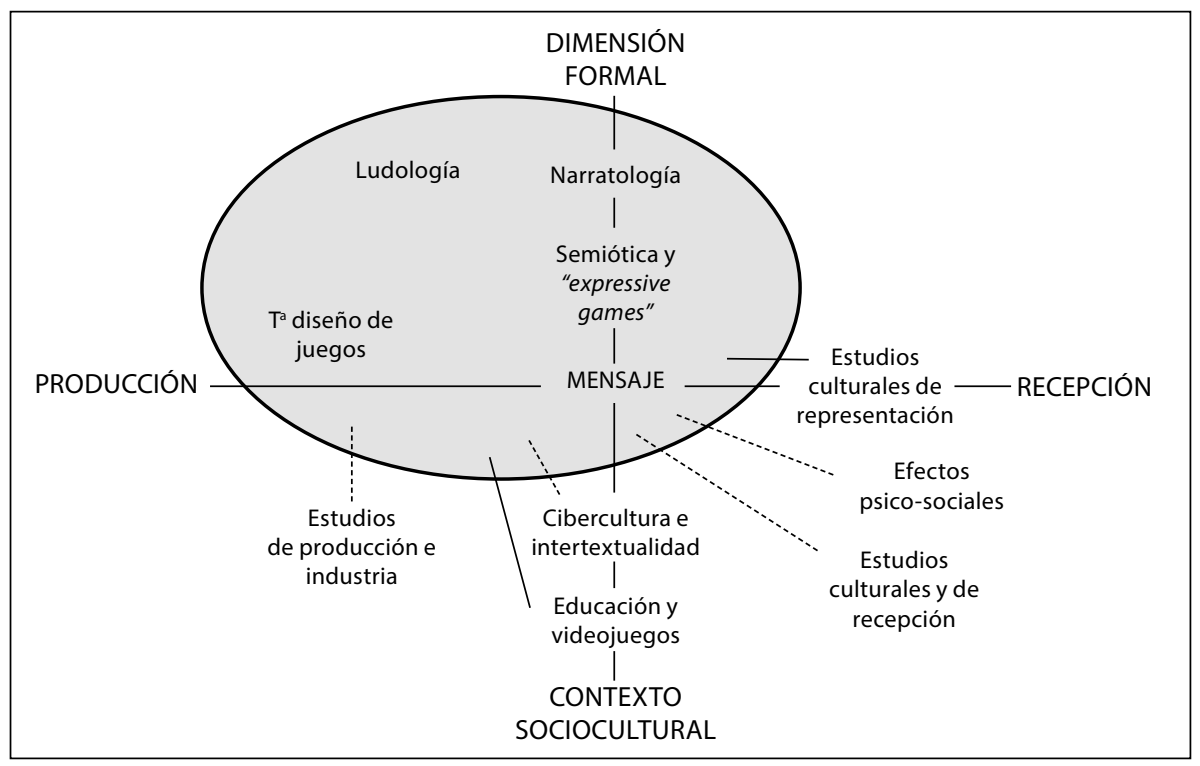

Figura 1: Perspectivas de análisis de videojuegos, extraído de Pérez Latorre (2010: 29).

El presente artículo se focaliza en el área de la semiótica, específicamente en los estudios discursivos. En los apartados que siguen se profundizará respecto a ambos temas.

\section{Concepción de discurso desde una perspectiva lingüística y el desplazamiento hacia discursos digitales}

En un sentido estricto se ha definido discurso como un término ambiguo, diverso, polisémico, difuso o sin sentido unívoco (van Dijk, 2000). Sin embargo, desde una mirada más amplia, este puede ser entendido como el uso de la lengua por los hablantes, considerando toda interacción verbal, ya sea oral o escrita. Al tener relación con el uso del 
lenguaje se puede entender como un acto de comunicación; al respecto, van Dijk señala que "las personas utilizan el lenguaje para comunicar ideas o creencias (o para expresar emociones) y lo hacen como parte de sucesos sociales más complejos" (2000:22).

Al profundizar en esta idea, se observa que el discurso involucra a más de una persona -quien produce y quien recibe el mensaje-; esta relación puede darse en situaciones presenciales o diferidas. Otro punto interesante que se destaca es que los sujetos se comunican no solo en cuanto a individuos sino, también, en cuanto a actores sociales. Por lo tanto, los participantes, además de utilizar el lenguaje para expresar ideas, también son parte de interacciones económicas, políticas o culturales concretas (van Dijk, 2000).

De este modo, al considerarse el uso del lenguaje, la comunicación y la interacción como niveles complementarios, se comprende que el discurso es un fenómeno sociocomunicativo. Por consiguiente, "hablar de discurso es, ante todo, hablar de una práctica social, de una forma de acción entre las personas que se articula a partir del uso lingüístico contextualizado" (Calsamiglia \& Tusón, 1999:15).

Los discursos se pueden clasificar de variadas formas dependiendo de los criterios que el analista considere. Una de las formas más comunes consiste en guiarse por la distinción de una determinada estructura. No obstante, dicha organización constituye solo la superficie de un fenómeno comunicativo más complejo. En efecto, la estructura está dada por aspectos que no se pueden entender utilizando solo el conocimiento lingüístico; se debe utilizar también el entorno social donde los discursos desempeñan determinadas funciones. Para van Dijk "esto vale no solo para una descripción del discurso como uso del lenguaje, sino también para sus otras dimensiones, a saber, del estudio del discurso como comunicación de creencias o como forma de interacción social" (2000:27).

Como se aprecia en los párrafos anteriores, el discurso no solo se limita a una serie de enunciados ordenados de acuerdo con una estructura, sino que se entiende como forma de comunicación. Según Albaladejo (2011) la tecnología ha propiciado una nueva forma de prácticas sociales; de este modo ha surgido una nueva clase de discurso mediado por entornos computacionales que tiene carácter multimodal, es decir, que contiene elementos visuales, acústicos, lingüísticos y no lingüísticos. Este discurso digital es "producido en entornos de mediación tecnológica, principalmente a través de internet, y suele desarrollarse en plataformas que permiten intercambios y que delimitan, de algún modo, las posibilidades y potencialidades comunicativas del usuario" (Vela \& Cantamutto, 2015:135).

Profundizado en la idea propuesta antes, Kress (2003; 2004; 2005a y 2005b), Kress y van Leeuwen (2001) y Vela (2005) plantean que debido a la influencia de los nuevos medios han emergido nuevos géneros electrónicos entre los que destacan el correo electrónico, los chats, las páginas web, los foros de debate y las weblog. De acuerdo con Vela (2005), estos son "algunos de los ejemplos que pueden ayudar a completar la enorme lista de nuevos géneros surgidos en los espacios de interacción propiciados por la Red" (2005: 29). A esta lista, pueden agregarse otros géneros electrónicos tales como los SMS y los videojuegos. 
Uno de los aspectos más destacables que emerge de los párrafos anteriores es que los nuevos géneros, además de ser variados, también presentan características propias. Al respecto de esto, Vela y Cantamutto (2015) señalan que el discurso digital no es una mera transferencia de un discurso que puede nacer desde la oralidad o desde la escritura a un soporte digital, sino que este posee características propias que obviamente pueden incluir insertos orales o escritos. Siguiendo a Herring (1996; 1999), las interacciones que se desarrollan en los discursos digitales, pueden darse a través de internet, computadores y otros dispositivos tecnológicos como teléfonos o tablet. Esta autora, agrega que estas interacciones aun cuando presentan trastornos en la adyacencia, variados solapamientos y falta de coherencia y continuidad en el desarrollo de los temas, son muy estimadas por los usuarios. En estrecha relación con lo planteado antes, los nuevos géneros electrónicos presentan dos aspectos que son relevantes para este estudio: en primer lugar, los contextos de producción y recepción de estos discursos electrónicos están mediados por las Tecnologías de la Información y Comunicación; como segundo aspecto, es relevante señalar que como producto, es decir, como texto, se presentan en un formato digitalizado (Vela, 2005).

De acuerdo con Vela y Cantamutto (2015) para analizar un discurso digital, desde el contexto de la interacción, el analista cuenta con un conjunto de datos que manifiestan una naturaleza muy particular. Este conjunto está compuesto por tres elementos: la multimodalidad, la multisimultaneidad y la falta de copresencia. Para los intereses de este artículo, el ámbito de la multimodalidad resulta vital para el análisis de un videojuego como discurso digital. En el siguiente apartado se profundizará esta idea.

\section{Recursos semióticos: constituyentes de un videojuego}

Los nuevos medios de comunicación e información presentan características que son distintas de los medios tradicionales tales como los libros, por ejemplo. Los primeros entregan mayores potencialidades para la acción por parte de lectores, escritores y creadores de una forma interactiva, lo que implica que los sujetos pueden interactuar y participar de los procesos de elaboración y construcción del conocimiento (Kress, 2005). La importancia del concepto de multimodalidad al momento de pensar en estos nuevos medios de comunicación e información radica en el surgimiento de nuevos modos de representación y comunicación que significan un cambio de paradigma en la alfabetización (Mangui, 2010; Mangui \& Córdova, 2011).

Como se señaló en el apartado anterior, Kress (2003; 2004; 2005a y 2005b); Kress et. al (2001) y Vela (20015) señalan que el surgimiento de los nuevos medios, ha traído consigo la proliferación de nuevos géneros electrónicos en los que las imágenes, los sonidos, la música, los gráficos, las fotografías, los esquemas, las fórmulas, los colores, las caricaturas, entre otros modos, ocupan un lugar protagónico tanto en su configuración como en las nuevas formas de alfabetizarse, llegando incluso a superar la importancia del texto escrito.

De acuerdo con Hodge y Kress (1988) cada grupo social escoge distintos recursos y diferentes medios para crear significados con el fin de cubrir sus necesidades de comuni- 
cación y representación. Estos modos o recursos semióticos presentan restricciones materiales (Mangui \& Córdova, 2011) y, además de utilizarse para crear significados, conforman el abanico de posibilidades con las que cada cultura trasmite o registra el conocimiento. El valor individual de los distintos recursos o modos de significación es importante para dar sentido a los textos y a los discursos tanto digitales como impresos; no obstante, su real valor emerge cuando estos se estudian y analizan de manera conjunta. Manghi y Córdova (2011) plantean al respecto la noción de orquestación semiótica que corresponde a una configuración semiótica compleja, compuesta por uno o varios modos de significar que son puestos en juego simultáneamente por los seres humanos. Para estos autores, la metáfora de la orquestación indica que hay varios elementos que son articulados por la persona que crea significados, quien actúa como el director de orquesta dirigiendo de manera armónica los recursos según su potencialidad, en pos de alcanzar sus objetivos, en este caso, comunicativos o retóricos. En este panorama sinfónico se puede distinguir la melodía, es decir, el tejido o entrelazamiento de modos desde el cual emerge el significado (Mangui \& Córdova, 2011).

Desde un punto de vista puesto en los modos o recursos semióticos constitutivos del videojuego, es posible señalar que estos son discursos multimodales electrónicos en los que interactúan diferentes modos de representación. De acuerdo con López (2013) existen 3 características que hacen de los videojuegos objetos singulares.

La primera característica sería su soporte informático. No se puede hablar de videojuego si no existe algún tipo de base informática que lo sustente y lo haga posible. Esa base informática genera algún algoritmo que se traduce en una acción en el juego. Sin informática no hay videojuegos. En segundo lugar, tiene que existir la posibilidad de intervenir en el juego a partir de un dispositivo físico. No solo tenemos un soporte informático sino que podemos interactuar con él a partir de algún tipo de dispositivo. Estos pueden ser muy variados, un teclado, un mouse, un joystick, un gamepad o directamente la superficie de una pantalla táctil. Si no intervenimos en ese algoritmo no se está jugando a videojuegos. La tercera característica general sería el resultado de las dos anteriores, la visualización del algoritmo con el cual se ha interactuado. Habitualmente el resultado de esa interacción se da a conocer a partir de alguna secuencia de imágenes. La interface gráfica es la que permite que interactuemos con la base informática de forma comprensible. Las imágenes es el lenguaje más importante en los videojuegos, aunque no el único. En el videojuego se combinan las imágenes, los sonidos y los mensajes escritos en un discurso unificado y coherente. No obstante, no se puede ignorar la potencia de las imágenes como vehículo privilegiado en este nuevo medio audiovisual (López, 2013: 39-40).

Uno de los aspectos más destacados que se puede extraer de la cita anterior se asocia con la relevancia que se les da a las imágenes en este tipo de discursos, aunque se reconoce la relación que existe con otros modos de representación. Es importante señalar que desde una perspectiva discursiva y multimodal, los videojuegos son discursos unificados y coherentes en los que interactúa una serie de modos o recursos semióticos 
de manera sincrónica. Cada uno de estos aportan diferentes significados al videojugador, que les da sentido y los comprende, tal y cual como se hace con el lenguaje verbal escrito u oral.

Desde un punto de vista analítico, Aarseth (2003) establece tres dimensiones del videojuego: gameplay, game-structure y game-world. La primera refiere a la experiencia de juego del jugador, es decir, el foco de esta dimensión está centrado en las estrategias, los motivos, las relaciones sociales y el conocimiento de los videojugadores. La segunda dimensión refiere a la estructura del juego, es decir, este componente se puede vincular con las reglas internas que rigen al videojuego, en otras palabras, aquí se considera la jugabilidad o incluso el género del videojuego. Por último, la tercera dimensión abarca el mundo del juego (game-world) a partir de los elementos que surgen de este. En esta dimensión cobran relevancia las imágenes, sonidos, mensajes y movimientos que configuran los elementos del juego (López, 2013).

Para efectos de este artículo, la dimensión de Game world es la que cobra mayor relevancia, dado que es desde esta, desde donde se puede describir la interacción de recursos semióticos que conforman un videojuego.

\section{Videojuego como discurso digital: aspectos metodológicos para la conceptualización de este objeto}

Los tres apartados anteriores han permitido revisar desde distintas teorías y perspectivas tanto los recursos constitutivos de los videojuegos, como sus relaciones con el discurso. El apartado actual se enfoca, en cambio, en describir el procedimiento mediante el que se elabora una definición de este medio electrónico desde la visión de los autores de este escrito.

Una de las etapas más relevantes en la construcción de esta definición se centra en la revisión y exploración de diferentes fuentes teóricas. Esta indagación permite a los autores de este escrito visualizar que las definiciones respecto a los videojuegos provienen de áreas tales como la educación (Grupo F9, 2000; Gómez et al., 2003; Mendiz et al, 2003; Pérez et al., 2003; De Aguilera \& Mañas, 2001; De Aguilera \& Mendiz, 2003; Sánchez et al., 2010) la ludología (Aarseth, 1997) y la informática (Nussbaum et al., 2003), entre otras; no obstante, no se evidencia una construcción teórica que asuma al videojuego como un discurso, es decir, que provenga desde el ámbito de la lingüística y desde una perspectiva multimodal.

La segunda fase metodológica consistió en el análisis de los siguientes videojuegos: Infamous, Second Son (2014); Just Dance (2014), Just Dance (2015); Never Alone (2014), Valiant Hearts (2014) y Batman Arkham Knight (2015). La observación de estos permitió identificar las características más relevantes de los mismos. De este modo se pudo determinar que los videojuegos tiene un aspecto narrativo que se expresa a través de cinemáticas, es decir, a partir de secuencias animadas que narran la historia (figura 2). 


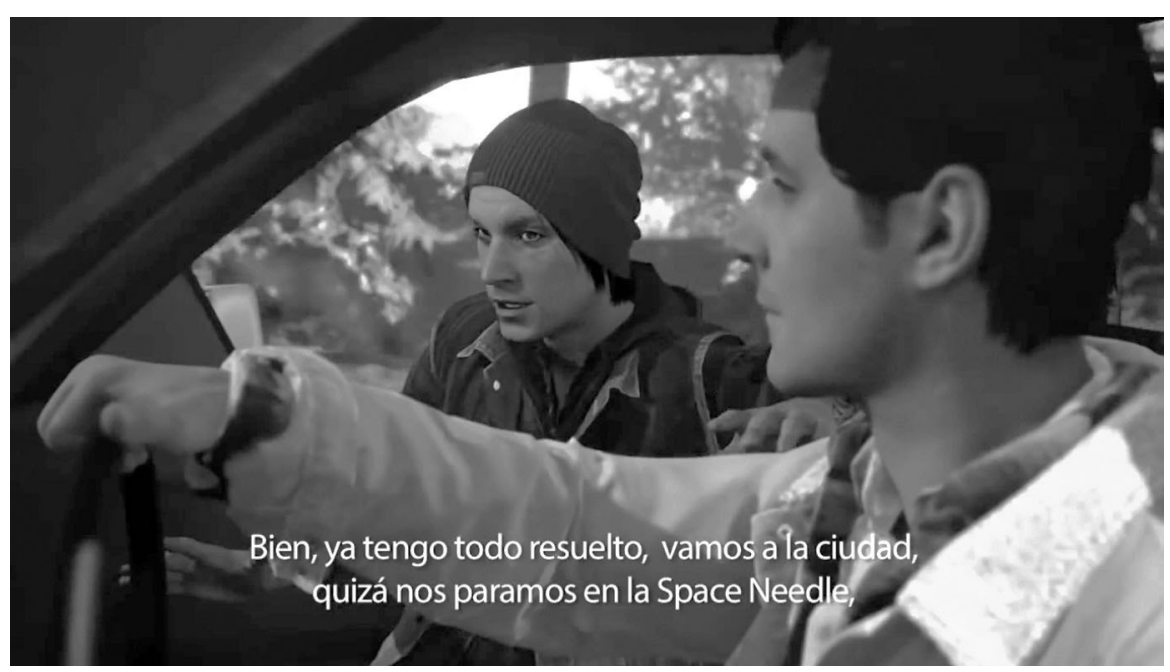

Figura 2: Captura de cinemática videojuego Infamous Second Son (2014)

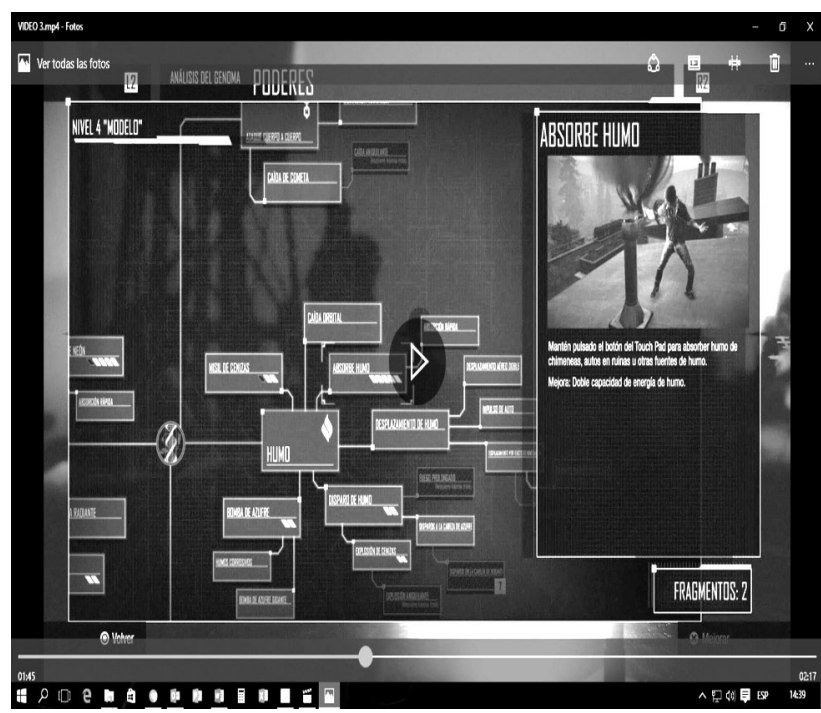

Figura 3: Captura de secuencia explicativa en la que se muestra cómo jugar. Videojuego Infamous Second Son (2014)

También, estos presentan secuencias explicativas y descriptivas mediante las que se enseña a jugar al videojugador (figura 3)

Por último, los videojuegos se constituyen por una serie de recursos semióticos tales como los iconos, los símbolos y los colores que indican la cantidad de vida que posee el personaje, los "poderes" activos, los objetivos del juego, el mapa y la posición geográfica en la cual está, entre otras (figura 4). 


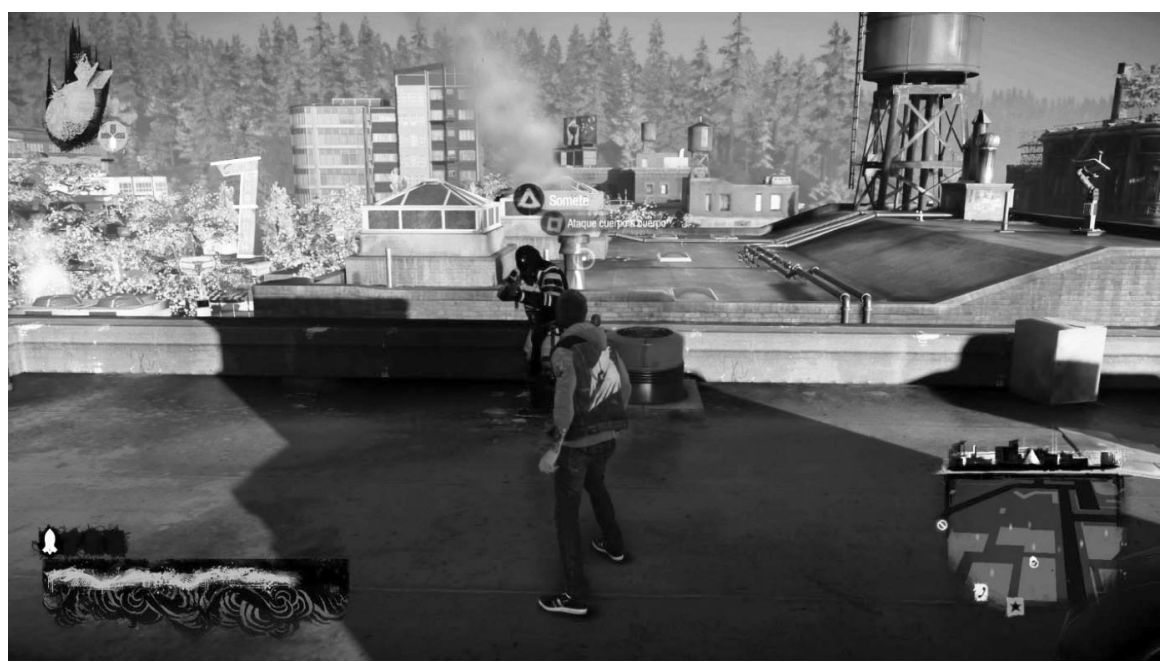

Figura 4: Captura in-game de videojuego Infamous Second Son (2014). Recursos semióticos.

A partir de las conceptualizaciones teóricas y el análisis, se ha determinado que los videojuegos son discursos multimodales electrónicos en los que las imágenes estáticas y en movimiento son el principal vehículo de transmisión de significados. Estas interactúan de manera simultánea con diferentes modos de representación (Kress 2003; 2004; 2005a y 2005b; Kress \& Van Leuween, 1996; 2001) tales como el sonido y el lenguaje verbal escrito y oral. Asimismo, en estos discursos multimodales se presenta el lenguaje icónico, los colores, los sonidos y la música interactuando en una orquestación semiótica que es comprensible para el videojugador.

Profundizando en esta concepción, resulta necesario puntualizar que el videojuego es un discurso electrónico asociado al ocio, al entretenimiento y también a la educación y que se vincula a otros discursos que provienen del mundo del cómic, del cine y la literatura. Ha pasado de ser considerado un entretenimiento infantil a un fenómeno cultural, social y artístico que se ha constituido en campo de estudio con sus propias problemáticas. Asimismo, y según palabras de López (2013), ha sido entendido como una forma de expresión audiovisual simple que ha evolucionado para ser considerado uno de los medios digitales con más posibilidades narrativas y de experiencia lúdica en la actualidad.

El videojuego es un cibertexto (Aarseth 1997) que tiene tres dimensiones constituyentes: gameplay, game-structure y game-world. Cada una de estas aporta aspectos sustanciales para la compresión de estos discursos multimodales electrónicos. Una de sus propiedades más relevantes es que no es muy diferente a un texto literario o un texto escrito, ya que, al igual que estos, requiere de lectores / receptores / visualizadores que deben tomar decisiones con el fin de dar sentido a lo que se lee / recibe / visualiza. De este modo, los videojuegos requieren de videojugadores que comprendan y signifiquen las representaciones semióticas que se presentan en la pantalla y den sentido a las orquestaciones semióticas que se muestran y escuchan. 
Los contextos de producción y recepción de este discurso electrónico están mediatizados por herramientas comunicativas relacionadas con las TIC, y como producto (texto) se presenta en un formato digitalizado (Vela, 2005). Por último, en términos estructurales el videojuego no es una construcción única, sino que en este interactúa una serie de secuencias de distinto orden, a saber: narrativas, descriptivas, explicativas y dialogales (Adam \& Lorda, 1999). De esta manera, en el videojuego confluyen secuencias narrativas que se presentan como textos escritos o en cinemáticas y que principalmente dan cuenta de la historia o trama. También hay secuencias descriptivas (presentadas a partir del lenguaje verbal e icónico) que permiten conocer los personajes, tipos de instrumentos u objetos, o los espacios en que se desarrolla la acción. Asimismo, hay secuencias explicativas que principalmente se muestran como mini discursos acompañados de recursos icónicos y visuales en los que presentan las instrucciones de cómo jugar o qué objetivos cumplir. Por último, hay secuencias dialogales que permiten una interacción entre el personaje principal que se está utilizando, con los otros personajes del juego.

\section{Conclusiones}

El presente escrito plantea desde un plano teórico un acercamiento a una definición de videojuegos. Como se puede rastrear en los apartados anteriores, las investigaciones y áreas teóricas que han analizado este discurso multimodal electrónico son variadas y ricas en cuanto a metodologías y enfoques. De acuerdo con Pérez Latorre (2010), desde el plano de la producción destacan las teorías de diseño de juegos, mientras que desde el plano de la dimensión formal, los estudios sobre narratología y semiótica. Precisamente desde esta última, se ha abordado la discusión en este artículo.

En comunión con lo planteado antes, los recursos semióticos o modos que constituyen al videojuego aportan diferentes significados al videojugador; estos, en una orquestación semiótica cohesionada y coherente que se produce de manera sincrónica, permiten a quien los recibe / lee / juega, les dé un sentido que cobra valor en la experiencia de juego.

La definición presentada en este artículo pretende establecer un concepto de videojuegos que proviene desde el plano discursivo y multimodal; de esta manera se busca contribuir en la conceptualización de un objeto de estudio que ha sido definido desde la informática, la educación, la psicología y otras disciplinas, pero que carece de un término que haya emergido desde los estudios de lingüística y multimodalidad.

Sin lugar a dudas, la conceptualización del videojuego como discurso multimodal electrónico deja abiertas varias interrogantes como las que siguen: ¿Cómo los videojugadores "leen" los videojuegos? ¿Cuáles son los procesos de comprensión que se realizan al estar frente a estos discursos? ¿Cómo se puede analizar desde un punto de vista estructural a estos discursos electrónicos? ¿Cuál es el área de estudios más propicia para abordar a estos discursos? Claramente todos estos cuestionamientos superan lo propuesto en este artículo y dan pie para nuevas conceptualizaciones y problemáticas. 


\section{Referencias bibliográficas}

Aarseth, E. (1997). Cybertext: perspectivas on ergodic literature. London: Johns Hopkins University Press.

Aarseth, E. (2003). Playing Research: Methodological approaches to game analysis, 5th Internacional Digital Arts and Culture Conference, Melbourne. Recuperado el 21 de marzo de 2011 en http:// www.cs.uu.nl/docs/vakken/vw/literature/02.GameApproaches2.pdf

Adam, J. M. E Lorda, C. (1999). Lingüística de los textos narrativos. Barcelona: Ariel.

Albaladejo, T. (2011). Accesibilidad y recepción en el discurso digital. La galaxia de discursos desde el análisis interdiscursivo. En F. Vílchez (ed.) Un nuevo léxico en la red. Editorial DYKINSON: Madrid.

Bernat, A. (2008). La construcción de conocimientos y la adquisición de competencias mediante el uso de los videojuegos. En B. Gros (coord.), Videojuegos y aprendizaje (pp. 93-112). Barcelona: Graó.

Calsamiglia, H. E Tusón, A. (1999). Las cosas del decir. Barcelona: Ariel.

De Aguilera, M., E Mañas, S. (2001). Atravesando el espejo (mediaciones tecnológicas y discursivas en las nuevas obras audiovisuales: el caso de los videojuegos). Comunicar, 17, 26.

De Aguilera, M., E Méndiz, A. (Coords.) (2003). Videojuegos y educación. Centro Nacional de Información y Comunicación Educativa. Ministerio de Educación y Ciencia. Serie Informes. Madrid.

Gómez, S., Esther, M. E Turci, I. (2003). Los efectos de los videojuegos: estudios y reflexiones. Centro Nacional de Información y Comunicación Educativa. Ministerio de Educación y Ciencia. Serie Informes. Madrid. http://ares.cnice.mec.es/informes/02/documentos/ind

Gros, B. (2008). Juegos digitales y aprendizaje: fronteras y limitaciones. En B. Gros (coord.), Videojuegos y aprendizaje (pp. 9-30). Barcelona. Graó

Grupo F9 (2000). Jugar con el ordenador, también en la escuela. Cuadernos de Pedagogía, 291, 52-54.

Herring, S. (1996). Linguistic and critical research on computer-mediated communication: Some ethical and scholarly considerations. The Information Society 12(2): 153-168.

Herring, S. (1999). Interactional Coherence in CMC. Journal of Computer-Mediated Communication 4(4).

Hodge, B. \& Kress, G. (1988). Social Semiotics. Cambridge: Polity.

Kress, G. (2003). Literacy in the new media age. London: Routledge.

Kress, G. (2004). Reading images: Multimodality, representation and new media. Information Design Journal + Document design, 12(2), 110-119.

Kress, G. (2005a). El alfabetismo en la era de los nuevos medios de comunicación. Málaga: Ediciones Aljibe.

Kress, G. (2005b). Gains and losses: New forms of texts, knowledge and learning. Computer and Composition, 22, 5-22.

Kirriemuir, J. E McFarlane, A. (2005). Literature review in games and learning. Futurelab report. Bristol. Futurelab

López, C. (2013). El videojuego como práctica discursiva contemporánea. Pokemón y la naturalización de la realidad social neoliberal. Tesis doctoral. Barcelona, Departamento de Psicología Social, Universitat Autonoma de Barcelona. 
Magui, D. (2010). Recursos semióticos del profesor de matemáticas: funciones complementarias del habla y los gestos para la alfabetización científica escolar. Estudios Pedagógicos 36, 2, 99-115.

Mangui, D. E Córdova, J. (2011). Definiciones y explicaciones multimodales: potencial semiótico en la enseñanza de la biología en la educación media. Revista Logos, 21, (2), 17-39.

Mangui, D.; González, D.; Echeverría, E.; Marín, C.; Rodríguez, P. E Guajardo, V. (2013). Leer para aprender a partir de textos multimodales: los materiales escolares como mediadores semióticos. Rexe, 12 (24), 17-41.

Méndiz A., Pindado J., Ruíz J., E Pulido J. M., (2003) Videojuegos y educación: Una revisión crítica de la investigación y la reflexión sobre la materia. Ministerio de Educación y Ciencia de España. En http://ares.cnice.mec.es/ informes/02/documentos/indice.htm

Mitchell, A., E Savill-Smith, C. (2005). The use of computer and video games for learning. A review of the literature. London. Learning and Skills Development Agency.

Montero, E., Ruiz, M. \& Díaz, B. (2010). Aprendiendo con videojuegos. Jugar es pensar dos veces. Madrid: Narcea.

Nussbaum, M.; Rosas, R.; Cumsille, P.; Marianov, V.; Correa, M.; Flores, P. E Salinas, M. (2003). Beyond Nintendo: design and assessment of educational video games for first and second grade students. Computers \& Education, 40(1), 71-94.

Pérez Latorre, O. (2010). Análisis de la significación del videojuego. Fundamentos teóricos del juego, el mundo narrativo y la enunciación interactiva como perspectivas de estudio del discurso. Tesis doctoral. Barcelona, Departament de Comunicació, Universitat Pompeu Fabra.

Pérez, D.; Postigo, I. E Sedeño, A. (2003). Un fenómeno consolidado. Los videojuegos en España. En Videojuegos y Educación. Centro Nacional de Información y Comunicación Educativa. Ministerio de Educación y Ciencia. Serie Informes. Madrid.

Sánchez, J.; Sáenz, M. E Garrido, J. M. (2010). Usability of a multimodal video game to improve navigation skills for blind children. ACM Transactions on Accessible Computing (TACCESS), 3(2), 7.

Sánchez, J.; Sáenz, M.; Tadres, A. \& Romo, F. (2009). Informe Final Agenda Videojuegos Comunidad Edujuegos TICC5, Centro Zonal Universidad de Chile. Santiago-Chile.

Van Dijk, T. (Comp) (2000). El discurso como interacción social. Estudios del discurso: introducción multidisciplinaria Vol. 1. Barcelona: Gedisa.

Vela, C. (2005). El correo electrónico: el nacimiento de un nuevo género. Tesis doctoral, Facultad de Filología, Universidad Complutense de Madrid, Madrid, España

Vela, C. E Cantamutto, L. (2015). Problemas de recogida y fijación de muestras del discurso digital en CHIMERA. Romance Corpora and Linguistic Studies 2, 131-155.

Ludografía: Videojuegos citados

Sucker Punch Productions (2014). Infamous, Second Son. Bellevue, Washington, EE. UU.

Ubisoft (2014). Just Dance. Francia

Ubisoft (2015). Just Dance. Francia

Upper One Games (2014). Never Alone. Alaska, EE. UU.

Ubisoft (2014). Valiant Hearts. Montpellier, Francia

Rocksteady Studies. Batman Arkham Knight (2015). Londres, Inglaterra 